\title{
Jonathan Bergmann and Aaron Sams, Flipped Learning: Gateway to Student Engagement, International Society for Technology in Education: Eugene, Oregon and Washington, DC, 2014; 169 pp.: ISBN 978-1-56484-344-9
}

Reviewed by Romina Plešec Gasparič ${ }^{1}$

There are two main reasons for the book Flipped Learning: Gateway to Student Engagement being an interesting read. The first is that the book discusses a relatively new concept, dating back to only 2006. The second is that it is written by the pioneers of the concept of flipped learning. Both reasons add to high expectations for this book.

The authors of the book, Jonathan Bergmann and Aaron Sams, both have teaching experience and were in fact colleagues when they started developing the idea of flipped learning. They were both teaching high school chemistry

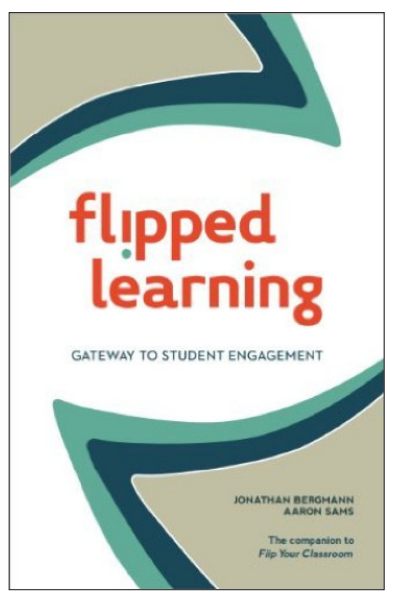
and shared a common vision: 'to put our students first so they could develop both cognitively and affectively' ( $\mathrm{p}$. ix). From their initial collaboration and the idea of flipping, stemmed a numerous online community of educators interested in flipping their teaching, the Flipped Learning Network (flippedclassroom.org) with a membership of over 20,000 in 2014 .

The book Flipped Learning: Gateway to Student Engagement is divided into two halves. In the first four chapters, the authors explain their background and aim to persuade the reader about the efficiency of the presented concept. Bergmann and Sams substantiate their thesis of flipped learning being a unique experience for each teacher and their class by including stories from a wide range of subject matter teachers, such as math, chemistry, physical education, biology, history, English and science (Chapters 5 to 11). There is also a story by a primary school fifth-grade teacher who flips her classes (Chapter 12) and a story of flipping professional development courses for teachers (Chapter 13). The final chapter summarises the teachers' stories, reviews the benefits of flipping,

1 University of Ljubljana, Faculty of Education, Slovenia; Romina.PlesecGasparic@pef.uni-lj.si. 
and even suggests that school administrators should flip their staff meetings to make better use of face-to-face time and thus empower teachers.

The book cover presents the book as a 'revolutionary education philosophy' taken to the next level. This refers to Bergmann and Sams' previous book, Flip Your Classroom: Reach Every Student in Every Class Every Day (2012), in which the authors focused mainly on producing high-quality videos for students, while in Flipped Learning, the classroom is truly student-centred and the teacher individualises instruction in order to engage each student. The book offers a general introductory look into the concept of flipped learning and indicates possible further exploration. The authors have expanded these primary notions by writing four more books dedicated to different subjects of flipping - a book series that supports flipped learning in five topic areas: science, math, English, social studies, and the elementary classroom.

Bergmann and Sams define flipped learning as an instructional model in which direct instruction is delivered individually through videos. The amount of whole-class instruction is minimised and time and space are given to other student grouping forms and activities, such as problem-based learning, discussion, inquiry, project work, etc. Throughout the book, the 'One Question' that the authors pose in the Introduction, is a common thread and this question is "What is the best use of face-to-face time with students?" (p. 3). Bergmann and Sams insist that this is the question that is the core of flipped learning and one that each teacher should ask constantly. Moreover, they believe each teacher should provide a unique and individual answer to it, according to the needs of their own students.

The concept of flipped learning appeared in 2006 and has passed several developmental stages since then, which also affected the terminological aspect of the concept. Originally, the concept of the flipped classroom, as it was then called, was based on the use of video as a medium of content transfer, while the teacher was at the centre of instruction. In the next developmental stage, the concept called 'the flipped mastery model' remained focused on the teacher's transfer of knowledge, but students' learning pace was taken into account and features were added to the videos that enabled adapting to the learners' needs. The last stage of development brought about the term 'flipped learning' with the student being the centre of the classroom and instructional strategies implemented with the aim of creating deep and lasting knowledge. The authors suggest that the teacher should not be the focus of instruction and that flipped learning supports student-focused processes. They note that teachers should provide quality and rich learning experiences for students and that flipping their class enables them to do so. However, they do not explain thoroughly 
what those qualities and rich learning experiences might be. Some further references to other authors exploring (e.g. group work, active learning, problembased learning, project work, etc.) might be beneficial to the book.

Bergmann and Sams constantly remind the reader to adapt the implementation to their own educational setting and be prepared that it is a lasting process, not an overnight change that would give evidence of flipped learning being an effective approach to teaching and learning. The authors emphasise the importance of personal experience and express the belief that the concept is worth implementing. The reader should keep in mind, that flipped learning is not a concrete, practical teaching strategy. Rather, as Bergmann and Sams often repeat, it is a combination of different effective teaching strategies, employed in different ways by different teachers. This makes flipped learning classes hard to compare and to make generalisations about them. A reader, interested in a more thorough research basis of the flipped learning concept, should look into the studies of Overmyer (2014), Strayer (2007) and others who have examined flipped learning both quantitatively and qualitatively.

Although the book could be upgraded by including an overview of research in this field, it still manages to provide a sound and common-sense idea on how to free up class time in order to carry out interactive and interesting learning activities which students will enjoy and benefit from. The authors emphasise that a one-size-fits-all approach to education is undoubtedly a failed one. Instead, they defend the notion that students should learn the same content but choose how they want to learn it. They advocate several grouping options: individual instruction, pairwork, and cooperative learning or, better yet, a mixed grouping organisation, with all those options being implemented at the same time; and several different teaching methods: reading, explanation, demonstration, etc. The book is encouraging and inspirational, offering many stories of real-life teachers, explaining how they implemented flipped learning into their own practice. Teachers share their ups and downs with flipped learning and admit to having to input a lot of effort, time and creativity to implement this innovation. Theirs are stories of success and an inspiration to teachers who also want their students to be more satisfied and achieve better learning results. Moreover, flipped learning enables more differentiated, democratic and equitable learning for all students.

The reader unfamiliar with the concept of flipped learning will find firsthand information about it from its founders as well as practising teachers. The book is a recommended starting point for teachers looking for ways to free up their class time in order to make teaching and learning more interactive and meaningful. 


\section{References}

Bergmann, J., \& Sams, A. (2012). Flip your Classroom: Reach Every Student in Every Class Every Day. Washington: International Society for Technology in Education.

Bergmann, J., \& Sams, A. (2014). Flipped Learning: Gateway to Student Engagement. Washington:

International Society for Technology in Education.

Overmyer, G. R. (2014). The Flipped Classroom Model for College Algebra: Effects on Student

Achievement (Doctoral dissertation). Fort Collins: Colorado State University.

Strayer, J. F. (2007). The Effects of the Classroom Flip on the Learning Environment: a Comparison of

Learning Activity in a Traditional Classroom and a Flip Classroom that Used an Intelligent Tutoring

System (Doctoral dissertation). Columbus: The Ohio State University 